\begin{tabular}{|c|c|c|c|c|c|c|c|c|c|c|c|}
\hline \multirow{2}{*}{ Q1) } & C & $\mathbf{D}$ & $\mathbf{E}$ & $\mathbf{V}$ & 1 & 1 & 4 & 3 & Dispatch: 11.3 .08 & Journal: CDEV & CE: C.N. Priya \\
\hline & \multicolumn{4}{|c|}{ Journal Name } & \multicolumn{4}{|c|}{ Manuscript No. } & Author Received: & No. of pages: 16 & ME: Senthil \\
\hline
\end{tabular}

Child Development, May/June 2008, Volume 79, Number 3, Pages 561-576

\title{
To Give or Not to Give: Children's and Adolescents' Sharing and Moral Negotiations in Economic Decision Situations
}

\author{
Michaela Gummerum, Monika Keller, Masanori Takezawa, and Jutta Mata \\ Max Planck Institute for Human Development
}

\begin{abstract}
This study interconnects developmental psychology of fair and moral behavior with economic game theory. One hundred eighty-nine 9- to 17-year-old students shared a sum of money as individuals and groups with another anonymous group (dictator game). Individual allocations did not differ by age but did by gender and were predicted by participants' preferences for fair allocations. Group decision making followed a majority process. Level of moral reasoning did not predict individual offers, but group members with a higher moral reasoning ability were more influential during group negotiations and in influencing group outcomes. The youngest participants justified offers more frequently by referring to simple distribution principles. Older participants employed more complex reasons to justify deviations from allocation principles.
\end{abstract}

Imagine that somebody gives you $\$ 10$ and tells you that you may share this money with an anonymous person you will never meet. There is nobody observing you, and there seems to be no reason why giving part of the money to the other will benefit you. What would you do? In economic game theory, this scenario is called the dictator game. Over the past decades, economists have examined how adults divide real money with anonymous others in this game and have interpreted their allocation decisions as reflecting self-interest or norms of prosocial or fair sharing. Rarely have economists been interested in developmental questions. Conversely, developmental psychologists have long been investigating fair and prosocial behavior in children and adolescents without taking notice of the debate in economics. Because the dictator game differs from tasks typically used in research on fairness and moral development, connecting these two research traditions seems to be a promising interdisciplinary endeavor. In line with economic research, we used the real-life sharing situation of the dictator game with children and adolescents.

\footnotetext{
We would like to thank all students and teachers at the Fichtenberg Gymnasium, Französische Gymnasium, and Grundschule an der Bäke for their participation; and Silke Atmaca, Dana Baltruschat, Susanne Baum-Deierlein, Agnes Brandt, Thomas Canz, Nellie Hankonen, Maren Hoffmann, Abiba Saibou, Sonja Schulze, Wiebke Seefeldt, and Erna Schiwietz and her team for help in data collection and analysis. Many thanks to Yaniv Hanoch and our colleagues at the Center for Adaptive Behavior and Cognition for comments on earlier versions of this manuscript, Anita Todd and Jutta Miller for editing, and Gerd Gigerenzer for his continuous support.

Correspondence concerning this article should be addressed to Michaela Gummerum, School of Psychology, University of Plymouth, Drake Circus, Plymouth, Devon PL4 8AA, United Kingdom. Electronic mail may be sent to michaela.gummerum@ plymouth.ac.uk.
}

There were three goals in the current research. The first was to find out whether children's and adolescents' allocations in the dictator game using real money differ from those of adults and across development. The second goal was to investigate whether participants' allocations would be influenced by psychological variables that have been shown in previous developmental research to affect fair and moral behavior. The third goal was to assess how groups of three peers achieve a common decision in group negotiations, and how they justify their offers to each other. We were specifically interested in whether participants with a certain allocation preference differ in influence during the group discussion, and whether level of moral development is related to gaining social influence in the group. The following sections will review previous research from economics and psychology that will help frame these questions in more detail.

\section{Research with the Dictator Game}

The dictator game was designed to measure fairness preferences (Kahneman, Knetsch, \& Thaler, 1986) and is widely used in economic research. In the simplest case, participants are paired with an anonymous other player. One of the players, the proposer or dictator, makes an offer of how to split (or not) a given sum of money with the other. The other player, the responder, can only accept the offer, and thus the money is shared according to the suggestion of the proposer. The game is played only

(C) 2008, Copyright the Author(s)

Journal Compilation (C) 2008, Society for Research in Child Development, Inc. All rights reserved. 0009-3920/2008/7903-0005 
once, so the responder cannot reciprocate or punish offers by the proposer.

Studies with adults (e.g., Forsythe, Horowitz, Savin, \& Sefton, 1994; Hoffman, McCabe, Shachat, \& Smith, 1994) have demonstrated that dictators offer on average between $20 \%$ and $30 \%$ of the original sum to the responder with the most frequent offers being either zero or half. Economists have interpreted proposers' positive offers in one-shot dictator games as an indication of other-regarding or social preferences (Camerer, 2003). Dictators not only seem interested in maximizing their own monetary payoff but also take into account the other's payoff and norms of sharing.

Only a handful of studies have examined developmental trends in the dictator game. Harbaugh, Krause, and Liday (2000; Harbaugh \& Krause, 2000) examined how students in 2nd, 4th/5th, 9th, and 12th grade (in dictator games) shared 10 tokens that could be exchanged for money or toys after the experiment. Although dictators in the three older groups offered, on average, between $10 \%$ and $20 \%$, second graders offered less than $10 \%$ of the original resources. Bettinger and Slonim (2006) found a similar age effect in children from low-income families. In a study by Sally and Hill (2006), the dictator game offers of 6- to 10-year-old normally developing children did not differ from offers of children with autistic spectrum disorders.

\section{The Dictator Game and Its Connection to Justice and Moral Reasoning Research}

Development of distributive justice. The dictator game shows similarities to allocation tasks used in research on the development of distributive justice (e.g., Damon, 1975, 1977) or reward allocations (e.g., Hook \& Cook, 1979). In these studies, participants allocate rewards to hypothetical group members who have worked together on a task and are characterized by certain features (e.g., age, effort, need, input). This research revealed distinct age differences in children's allocations and reasoning. Preschool children tended to share according to self-interest or salient characteristics (e.g., age, size), and young elementary school children allocated according to equality (i.e., everybody gets the same). Older elementary school children interpreted fairness in terms of ordinal equity (what is deserved depending on input). From age 8 , children considered special needs of people, and from late childhood onward, they tried to coordinate different modes of justice and pay attention to particularities of a given situation. The finding that younger children decide more in favor of their self- interest is also reflected in a meta-analysis on the development of prosocial behavior by Fabes and Eisenberg (1998). Significant age differences emerged between the sharing behavior of infants, preschool children, children, and adolescents, with older participants being more prosocial than younger children.

Even though both the dictator game and the distributive justice tasks investigate people's fairness allocations, there are some major differences between these methods. Decisions in the dictator game are real-with players mostly receiving money-whereas most distributive justice studies have used hypothetical scenarios (but see McGillicuddy-De Lisi, Daly, \& Neal, 2006). In the dictator game, the receiver is anonymous, whereas in distributive justice tasks, the receivers are described by certain characteristics. In the current study, we investigate whether the age differences found for children's and adolescents' allocations in distributive justice tasks will similarly be obtained for monetary allocations in the anonymous dictator game and whether participants' allocation decisions in the dictator game can be predicted by an independent fairness preference measure.

Development of moral reasoning and behavior. In the dictator game, the self-interest of the dictator conflicts with the norm of fair sharing. This is similar to dilemmas used in studies on the development of (prosocial) moral reasoning, in which a person's (selfish) desires conflict with the needs of others and prosocial norms (Eisenberg, 1986; Keller \& Edelstein, 1993). Similar to reasoning about moral dilemmas (Kohlberg, 1984; Gibbs \& Widaman, 1982), this research has shown that moral reasoning develops along a sequence of developmental levels based on the ability to differentiate and coordinate perspectives. Preschoolers and young elementary school children focus on authority, hedonistic, and (primitive) needs-oriented reasons, and older elementary school children on stereotypic reasons for being a good or bad person and pragmatic exchange rules (preconventional, Levels 1 and 2). Internalized affective reasons (e.g., guilt, sympathy) and internalized norms emerge in early adolescence, whereas concerns with society, rights, and justice are topics in late adolescence (conventional, Levels 3 and 4). Finally, at the highest levels of moral reasoning (postconventional, Levels 5 and 6), adults reason in terms of social contracts, universal rights, and principles that take priority over particular societal laws.

We are interested in whether participants' level of moral reasoning influences the allocation decisions of individuals in the dictator game. Cognitive-developmental theories have generally maintained that the maturity of children's reasoning in moral dilemmas is 
associated with the quality of their prosocial or moral behavior and that people who reason on higher moral levels also show greater social sensitivity and feelings of responsibility (Blasi, 1980; Eisenberg, 1986; Krebs \& Van Hesteren, 1994). Psychologists from other research traditions judge the relationship between moral reasoning and behavior more pessimistically. Haidt (2001) argued that moral reasoning should not be seen as a cause of an individual's moral judgment and moral behavior but rather as a post hoc justification for behavior. However, he postulates that moral reasoning ability may be crucial when people try to influence and change each other's moral judgments and behaviors in social situations. In the present study, we follow up on this hypothesis and explore whether level of moral reasoning is related to gaining social influence during group discussions between peers.

\section{Sharing Decisions in a Group Context}

Peer relations present a crucial context for moral development (Piaget, 1965; Turiel, 1983) and interaction between peers stimulates moral growth through cognitive conflict (Berkowitz \& Gibbs, 1983; Walker, Hennig, \& Krettenauer, 2000). Research has typically focused on individual outcome variables of (moral) conflicts between peers (e.g., increase in level of moral reasoning after discussion) or has examined the (moral) negotiation and conflict resolution strategies of friends and siblings (Berkowitz \& Gibbs, 1983, 1985; Ram \& Ross, 2001).

In this study, we examine the process by which groups of three peers reach a common allocation decision in the dictator game and how level of moral reasoning helps group members gain social influence during group discussions. Using the paradigm of group decision making allows us to assess the processes of social influence among the three group members. This presents an attractive addition to moral development research because the question of how moral and fair decisions are influenced by group processes has not been investigated. To study group decision-making processes, we utilized the social combination approach (Davis, 1973; Stasser, Kerr, \& Davis, 1989) developed in social psychology. Its basic idea is to find a (mathematical) function that translates the individual group members' preferences into one group decision. We focus on the social judgment schema (SJS) model (Davis, 1996), which predicts that the group offer will be determined by a majority process. Group decision-making research has revealed that the majority process is a default rule employed by people to aggregate different opinions in a judgment task that has no obvious correct solution (Hinsz, Tindale, \& Vollrath, 1997; Stasser et al., 1989). When three children individually offer 10,10, and 4 of 20 coins in the dictator game, the SJS model predicts that the group will offer 10 coins. If the group deviates from the model and a group offer is lower than 10, it suggests that a selfish child was more influential than two prosocial children. Thus, a social combination approach to group decision making permits us to formally investigate the social influence of a specific group member on the final group decision.

Takezawa, Gummerum, and Keller (2006) applied this model to group decision making in the dictator game. They found that the group offers of sixth-grade students deviated from the prediction of a majority model in a selfish direction, whereas eighth graders followed a majority model. A prosocial majority was relatively more influential on the group decision in eighth grade compared to sixth grade. It was hypothesized that the higher moral reasoning ability of eighth graders may have made prosocial arguments more influential during the group discussion than in sixth grade. In the study reported here, we directly investigate the relationship between social influence and level of moral reasoning in a sample of children and adolescents.

Previous game-theoretical studies on group decision making have shown that adults behave in a more self-interested and less cooperative way in a group compared to individual contexts (e.g., Bornstein \& Yaniv, 1998; Schopler \& Insko, 1992). In contrast, Cason and Mui (1997) found that adult dictators tended to offer more in two-person groups than as individuals. As Song, Cadsby, and Morris (2006) point out, the discrepancy between these findings may be better explained if research takes into account the decision-making process in groups. It is important not to merely compare mean differences in individuals' and groups' allocations because group offers are determined by both the distribution of individual preferences in each group and the group decisionmaking process.

We decided to study groups of three children. First, to assess majority processes, a minimum number of three members is necessary. Second, studies on peer problem solving have shown that collaboration, especially in larger groups, may be more cognitively demanding for younger children (see Azmitia \& Perlmutter, 1989). Third, a theoretical analysis by Ohtsubo, Fujita, and Kameda (2004) suggested that a high-status group member may be more likely to exert influence in groups consisting of an even number of group members, a scenario we wanted to minimize in this study. 


\section{Justification for Allocations in Group Discussions}

An additional advantage of studying decisions of groups in the dictator game is that group members' justifications for offers can be assessed by analyzing the group discussions. These justifications give insight into how group members construct the dictator game situation and which aspects of this situation they regard as important. We investigated whether the justifications that children and adolescents spontaneously produce for certain dictator game offers mirror the reasoning employed in distributive justice tasks (e.g., equity, equality, need). According to Hook and Cook (1979), equality and self-interest concerns require people to pay attention only to the outcome dimension. Reasoning along these lines is thus cognitively easier, and such strategies are used more frequently by younger children than reasoning with reference to need, equity, and reciprocity, which involve a comparison of inputs and outputs and are more common in older participants.

Furthermore, adults often justify violations of moral norms are often justified through excuses that serve to make such violations morally legitimate, for example, through negatively stereotyping the responders, relabeling the situation, and diffusion of responsibility (Bandura, 1999; Bandura, Caprara, Barbaranelli, Pastorelli, \& Regalia, 2001). Because self-interested offers violate norms of fair sharing, such excuses may be additionally used to justify low offers, particularly among older children and adolescents (Keller, 1984).

\section{The Current Study}

The current study is a follow-up of an earlier study by Takezawa et al. (2006), who investigated sixth graders' and eighth graders' individual and group decisions in the dictator game and related participants' allocations to their fairness preferences and moral reasoning level. They found no significant age differences in the individual allocations between the two age groups. Fairness preferences but not moral reasoning level influenced individual decisions in the game.

We added two more age groups-elementary school children from 3rd grade and adolescents from 11th grade - to the previously studied participants from 6th and 8th grade. This allowed us to establish a more comprehensive developmental design, including both younger children who are quite different from the undergraduate participants so typically studied and adolescents who are closer in age. Takezawa et al. (2006) finding of no age differences in dictator game offers and in level of moral reasoning seems to contradict previous findings in developmental and economic research (e.g., Damon, 1977; Harbaugh et al., 2000) and might be attributed to the fact that the samples differed by only 2 years of age. For the present study, we predicted that the youngest participants would make lower individual offers in the dictator game than older participants. We expected that a fairness preference measure would predict individual allocation choices in the dictator game across all age groups. As for the effect of moral reasoning level, two alternative hypotheses are possible. Similar to Takezawa et al., we might not find an overall effect of moral reasoning on individual sharing. On the other hand, moral reasoning might be moderately related to individual dictator game offers in the present study of a sample with increased age variance. Furthermore, we predicted that group members with a higher level of moral reasoning would have more influence on the group decision than group members with lower moral reasoning abilities.

Previous studies on distributive justice development and the dictator game have generally not tested for or reported gender effects, but research on sharing and (prosocial) moral reasoning has found that, particularly among older children and adolescents, girls tend to respond more prosocially than boys (Fabes \& Eisenberg, 1998). Therefore, we expected that females would share more in the dictator game and exhibit a higher level of moral reasoning than males. Only same-gender groups are studied because the social dynamics of group members' conversations tend to differ between mixed and same-gender groups (Leman, Ahmed, \& Ozarow, 2005). Using same-gender groups thus allows for a comparison of group decision making between females and males of the same-age group.

Concerning justifications for offers, we predicted that the younger participants would more frequently refer to fairness (equality) or to self-interest to justify their offers, whereas older participants would use more complex justifications. Research on the development of ethnic and gender attitudes has found that children ascribe more positive attributes to their own group and more negative attributes to out-groups and essentialize differences between in- and out-groups (Bloom, 2004; Hirschfeld, 1995). Furthermore, reciprocity governs much of children's behavior and exchange of thoughts and feelings (Youniss, 1980). We therefore expected that higher offers would be justified by the attribution of positive characteristics to the other group and positive reciprocity. To justify lower offers, older participants were expected to use 
negative attributions such as stereotyping the other group and negative reciprocity.

\section{Method}

\section{Participants}

Participants were 39 students from 3rd grade $(M=$ 8.7 years; 21 girls, 18 boys), 45 students from 6 th grade $(M=11.5$ years; 27 girls, 18 boys $), 48$ students from 8th grade ( $M=14.1$ years; 33 girls, 15 boys), and 57 students from 11 th grade $(M=17.7$ years; 45 girls, 12 boys). Students from 3rd and 11th grade were recruited from an elementary school and a high school in the southwest part of Berlin, respectively. The 6th and 8th graders were from a bilingual high school in the central western part of Berlin; analyses of these participants' offers in two economic games is published in Takezawa et al. (2006).

All participants came from middle-class families. In each grade, about $85 \%$ of participants had parents with a German background and the remaining 15\% had at least one parent of another nationality (MiddleEastern, Eastern European, African, East Asian). Only students who brought a signed consent form from their parents were allowed to participate in the study.

To check whether the difference in school background between 6 th $/ 8$ th and $3 \mathrm{rd} / 11$ th grade made differences in the variables of interest, we compared sharing behavior in the dictator game and fairness preferences of the present 6th-grade participants with an additional sample of 6th graders drawn from the same school as the present 3rd-grade participants. Independent-samples $t$ tests revealed no differences (all $p \mathrm{~s}>$.10). Similarly, no significant differences were found concerning the fairness preferences of the present sample of 6th- and 8th-grade participants with two samples of same-aged peers drawn from the same school as the present 11th-grade participants (all $p s>.20)$.

\section{Procedure}

During the school day, three same-sex students from the same class were randomly selected and taken into a separate room by a female experimenter. Another female graduate student in the room ran the video equipment (not hidden from the participants) but was not involved in the interaction with the participants. Participants were told that they would play two consecutive games (dictator game and ultimatum game) with a different group of three anonymous same-sex and same-grade students. They were told that the other students could be from their own or another school and that neither group would know with whom they had played the game. Moreover, it was stressed that their decisions would not be revealed to classmates, parents, or teachers by the experimenters. Participants played the dictator and the ultimatum game in a counterbalanced order. In this study, we focus only on the dictator game.

Participants were instructed in the proposer role of the dictator game. After participants' understanding of the game structure was confirmed, they were asked to privately write down their individual sharing preferences on an answer sheet. Students inserted their answer sheet into an envelope collected by the experimenter. The group was then asked to discuss how much to offer to the other group. Each group had up to $10 \mathrm{~min}$ to come to a unanimous agreement. If groups had not come to a decision after $10 \mathrm{~min}$, they were prompted by the experimenter to finish the discussion within $2 \mathrm{~min}$. Discussions were videotaped and participants were aware of this. The adults left the room before the discussion started and returned at the end to ask about the group's decision.

About 2 weeks later, students filled out two questionnaires measuring fairness preferences and developmental level of moral reasoning. If requested by the class teacher, a discussion about fairness, prosocial behavior, and sharing was initiated and facilitated by the experimenter. The payment for the experiment, sealed in an envelope, was handed to each participant at the end of this session.

\section{Measures}

Dictator game. Students were instructed in the role of the proposer. It was pointed out that they could earn money in this experiment but that the amount of money they earned would depend on their group decision. They were given 20 coins, worth 10 cents each ( 2 euros total) in 3rd grade, 20 cents each (4 euros total) in 6th and 8th grade, or 30 cents (6 euros total) in 11 th grade. To make the stakes equally meaningful, they were based on the average weekly amount of pocket money children of that age would typically receive. Previous research has found no developmental differences in the way children of the present age groups conceptualize money and its value (Abramovitch, Freedman, \& Pliner, 1991; Berti \& Bombi, 1981). Participants were told that their group could determine how to share (if at all) the 20 coins between themselves and another anonymous group of three. It was pointed out that offers could range from 0 to 20 coins in steps of 1 coin. They were told that payment for each group member was the number of 
coins the group wanted to keep. For example, if a group wanted to keep 10 coins, each group member would receive 10 coins.

Fairness preferences. Fairness preferences were measured with two tasks (see Takezawa, 2003). In both tasks, participants had to select one of two hypothetical alternatives, allocating money to themselves and another person. In the first task, Alternative A gave self 15 (euros) and the other person 5 . Alternative B gave both 8 . In the second task, Alternative A gave self 15 and the other person 5, but Alternative B gave both 12. After participants chose Alternative A or B in each task, they had to indicate the desirability of their choice on a Likert scale (1, like it a little; 2 , somewhat like it; 3 , like it; and 4, like it very much). Thus, these tasks measure how much participants prefer an equal distribution (Alternative B) compared to an allocation that would leave them with a higher payoff (Alternative A) and vice versa.

For each task, individual choice and desirability ratings were combined and expressed on an 8-point scale (1, like Alternative A very much; 2 , like Alternative A; 3, somewhat like Alternative A; 4, like Alternative A a little; 5, like Alternative $B$ a little; 6, somewhat like Alternative B; 7 , like Alternative B; and 8, like Alternative $B$ very $m u c h$ ). Fairness preference is the average of the two 8-point scales; higher scores indicate higher preference for equal/fair allocations.

Moral reasoning. Developmental level of moral reasoning was measured with open-ended questions about two moral concepts of Gibbs and Widaman's (1982; see also Keller \& Edelstein, 1993) Sociomoral Reflection Measure. Participants were asked whether and why it is important to keep a promise, and whether and why it is important to help. Helping is a voluntary positive moral duty, whereas keeping a promise is a negative moral duty that one owes to everybody (Frankena, 1973). Reasons given were scored from Stage 1 to Stage 4 with transitional half stages according to the scoring manual of Gibbs and Widaman. Level 1 includes simple and stereotypic reasons (e.g., one must/does not have to keep a promise or help; it is nice to keep a promise/help; it is not nice to break a promise/not help; one will be punished if one does not keep a promise/does not help). Level 2 includes reasons such as simple reciprocity (so that others will also keep the promise/help) and anticipation of consequences for the relationship (otherwise one would not be friends anymore/this way one can get more friends). Level 3 focuses on impression making and trust in relationships (if I do not keep a promise/do not help, no one will trust me; they will think that I am not reliable) and conscience (bad conscience if one did not keep a promise/help). At Level 4 keeping a promise/helping is seen as necessary for the maintenance of relationships and for smooth interaction in society; individual responsibility for others' welfare is emphasized. Reasons referring to the postconventional Levels 5 and 6 could not be coded in the present sample. Inter-rater reliability for two independent raters was $87 \%$.

\section{Scoring of Justifications in Group Discussion}

A manual was developed for categorizing participants' justifications for offers in the group discussion. We differentiated two types of justifications:

\section{Unconditional preferences and justifications}

- Fairness. Explicit reference to fairness, justice, or democracy without further explanations as to why these concepts are important (e.g., "Because it is just"; "We always want to be fair").

- Egoism. Reference to own selfish or material desires without any further explanation (e.g., "Because I wanted to keep the money for myself"; "But we want to make more profit").

\section{Conditional attributions and justifications}

Group (positive/negative). Statements that attribute a social category, trait, or characteristic to the other group or express concern about how the participant's own group would look in the eyes of others. If used in a positive sense, participants attribute characteristics to the other group that bring it closer, make it more similar or likable to their own group, point out neediness of the other group, and they interpret anonymity of the other group in a positive way (e.g., "Look, maybe it's people like us, just like us"; "You'd rather share with them if they are friends than if they are strangers"; "We have to appear generous"). If used in a negative sense, participants employ attributes or characteristics that make the other group more dissimilar to their own group or create a (psychological) distance between the two groups. Statements in this category include those asserting that the other group does not need the money or those that interpret the anonymity of the other group in a negative way (e.g., "Maybe they are unfair people in the other group"; "Maybe they are not likeable, and they don't need the money").

Reciprocity (positive/negative). Statements through which participants put themselves in the position of the other group (role play) or imagine what the other group would do in their position. In positive 
reciprocity statements, group members point out that the other group would reciprocate or would also act in a generous way (e.g., "Imagine they'd give us a lot"; "Because one could well imagine that the others would do it, too"). Negative reciprocity statements assert that the members in the other group would not reciprocate or would act greedily as well (e.g., "I'll tell you why-because the others wouldn't give us anything either"; "I don't think they'd give us much either").

Hierarchical power (positive/negative). Statements that deal with status differences between the two groups. For example, one group has more power because it can determine the payoff, one group puts in more effort, and so forth. Used in a positive way, these status differences make the more powerful group responsible for the condition of the less powerful group (e.g., "That means we say how much they get and how much we get. Therefore, it is nasty to give only one coin"; "Because we bear the responsibility for the other group"). If used in a negative way, the higher status group is allowed to claim more money because it has more decision power or has invested more effort (e.g., "If I can decide, I will not give them

(a)

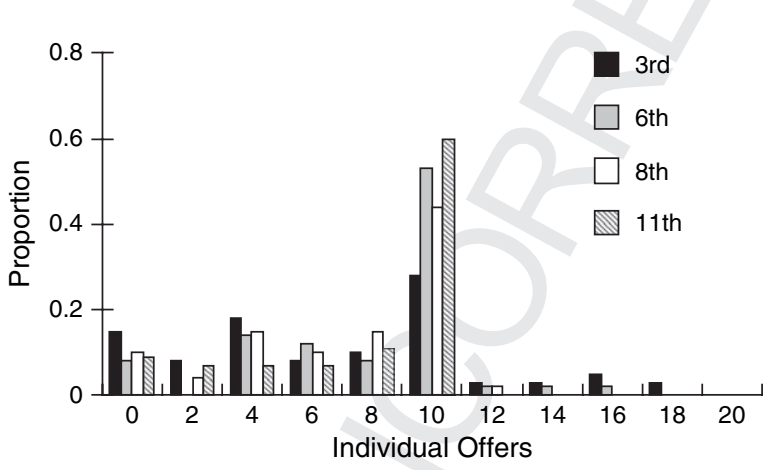

(c)

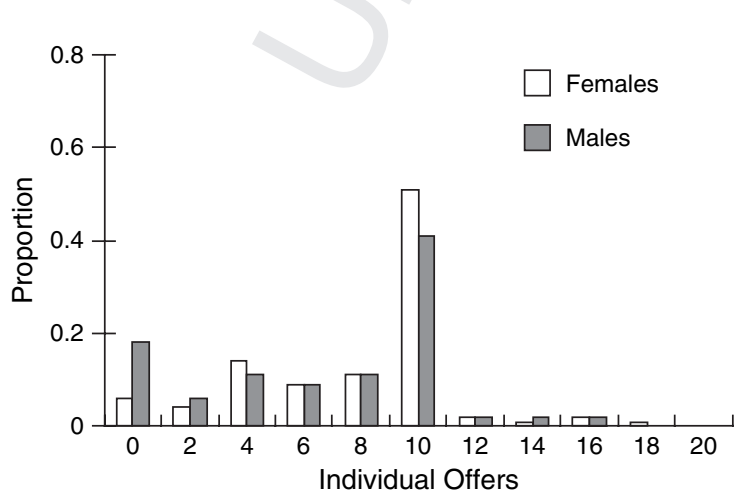

half"; "Therefore we have to get money for the work and time we invest in sharing").

In addition, some justifications were uncodable. These were justifications in which irrelevant explanations for an offer were given (e.g., "Because I like this number") or in which instructions were repeated.

Two independent raters coded 10 complete discussion transcripts. An agreement between two raters meant that both (a) marked the same text in the transcripts and (b) gave the same code for this piece of text. Inter-rater reliability was $78 \%$; discrepancies for codes were discussed to find the best solution.

\section{Results}

\section{Individual Offers in the Dictator Game}

Figure 1a and $\mathrm{c}$ displays the distributions of individual offers in the dictator game by grade and gender, and Table 1 shows the means and standard deviations for individual offers. The equal split (10 coins) was the modal offer in all grades and for both genders. A univariate analysis of variance (ANOVA)

(b)

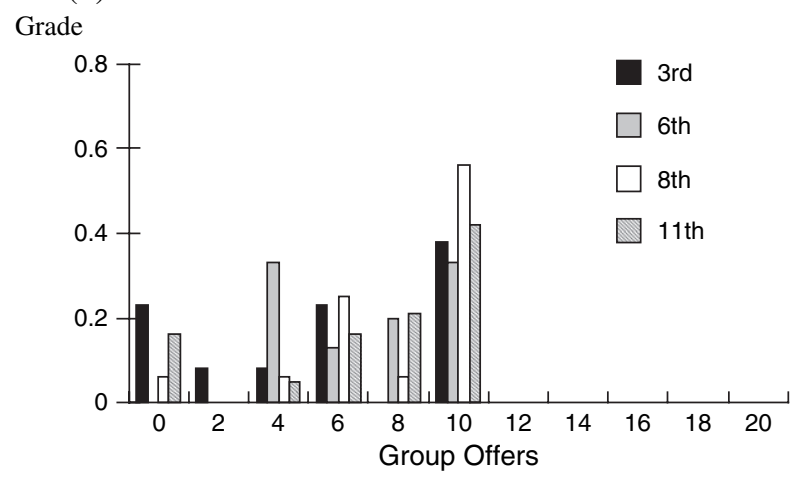

(d)

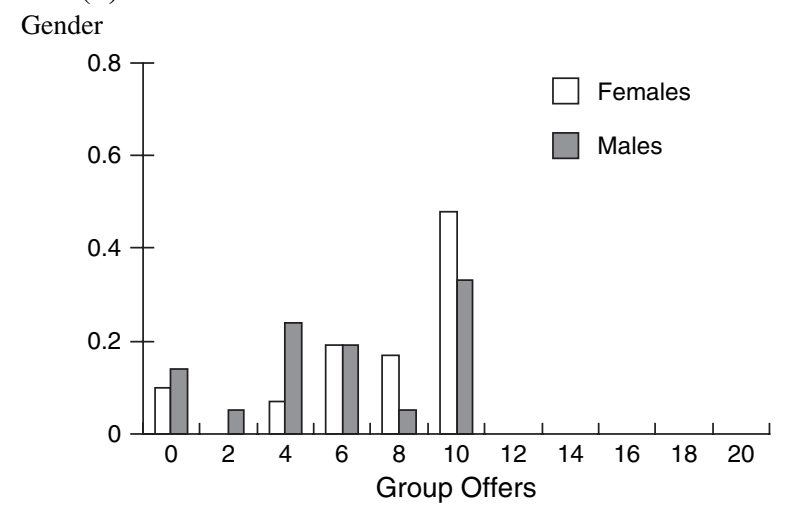

Figure 1. Distribution of individual and group offers (number of coins) in the dictator game by grade (a and b) and gender (c and d). 
with the independent variables grade and gender did not reveal a significant difference between the four grades concerning their mean individual offers in the dictator game, $F(3,189)=0.52, p=.67, \eta_{p}^{2}=.008$. However, a significant main effect for gender was obtained, $F(1,189)=4.80, p=.03, \eta_{\mathrm{p}}^{2}=.03$. As indicated in Figure $1 \mathrm{c}$ and Table 1, overall, boys $(M=6.94)$ made smaller individual offers than girls $(M=8.13)$.

As suggested by one anonymous reviewer, we used Epps and Singleton's (1986) characteristic function $(\mathrm{CF})$ test to compare the distribution of individual offers between grades. The CF statistic is asymptotically distributed as chi-square with four degrees of freedom; the test examines whether two samples of discrete data are likely to be from identical populations. Pairwise comparisons of distributions (adjusted critical $p$ value: $p<.0051$ ) revealed that the distributions did not significantly differ by grade.

\section{Fairness Preferences, Moral Reasoning, and Their Relation to Individual Offers}

A univariate ANOVA with the dependent variable fairness preference and the independent variables grade and gender revealed a significant main effect for gender, $F(1,156)=38.07, p=.00, \eta_{p}^{2}=.06$. Overall, females preferred equal splits more than males (see Table 1). Concerning moral reasoning, a $2 \times 4$ ANOVA showed significant main effects for grade, $F(3,155)=22.95, p=.00, \eta_{\mathrm{p}}^{2}=.32$, and gender, $F(1$, $155)=4.15, p=.04, \eta_{\mathrm{p}}^{2}=.03$. Post hoc Scheffé tests $(\alpha=0.05)$ revealed that moral reasoning level was significantly different between each of the four grades (all $p \mathrm{~s}<.01$ ), except between participants from sixth and eighth grade, whose moral reasoning level was

Table 1

Means and Standard Deviations of Individual Offers in the Dictator Game, Fairness Preference, and Level of Moral Reasoning by Grade and Gender

\begin{tabular}{|c|c|c|c|c|c|c|}
\hline & \multicolumn{2}{|c|}{$\begin{array}{l}\text { Individual } \\
\text { offers }\end{array}$} & \multicolumn{2}{|c|}{$\begin{array}{c}\text { Fairness } \\
\text { preference }\end{array}$} & \multicolumn{2}{|c|}{$\begin{array}{l}\text { Level of } \\
\text { moral reasoning }\end{array}$} \\
\hline & $M$ & $S D$ & $M$ & $S D$ & $M$ & $S D$ \\
\hline \multicolumn{7}{|l|}{ Grade } \\
\hline 3rd & 7.33 & 4.61 & 6.06 & 2.60 & 1.58 & 0.48 \\
\hline 6th & 8.11 & 3.12 & 6.37 & 2.08 & 2.21 & 0.56 \\
\hline 8th & 7.58 & 3.43 & 6.67 & 1.64 & 2.26 & 0.62 \\
\hline 11th & 7.82 & 3.29 & 6.50 & 1.69 & 2.67 & 0.47 \\
\hline \multicolumn{7}{|l|}{ Gender } \\
\hline Female & 8.13 & 3.33 & 6.78 & 1.56 & 2.35 & 0.63 \\
\hline Male & 6.94 & 3.94 & 5.71 & 2.51 & 2.01 & 0.65 \\
\hline
\end{tabular}

almost the same. Females' moral reasoning was on a significantly higher level than the moral reasoning of males (Table 1).

We conducted two separate regression analyses on individual offers in the dictator game as a function of fairness preference or level of moral reasoning, respectively. Fairness preference predicted individual offers ( $\left.\beta=0.36, t=4.87, p=.00, R^{2}=.12\right)$. The higher the participants' fairness preference, the more they allocated in the dictator game. Level of moral reasoning did not predict individual offers in the dictator game $\left(\beta=0.03, t=0.32, p=.75, R^{2}=.00\right)$.

\section{Group Offers in the Dictator Game}

Figure $1 \mathrm{~b}$ and $\mathrm{d}$ shows the distribution of group offers by grade and gender, and Table 2 displays the means and standard deviations for group offers. Except for sixth grade, the equal split was again the modal group offer in all grades and for both genders. A $2 \times 4$ ANOVA with the independent variables grade and gender did not reveal any significant main or interaction effects.

\section{Group Decision-Making Process: Social Combination Approach}

To investigate the process of group decision making from a social combination perspective, we

Table 2

Means and Standard Deviations of Observed Group Offers, the SJS Model's Predictions, and Absolute Difference Scores by Grade and Gender

\begin{tabular}{|c|c|c|c|c|c|c|}
\hline \multirow[b]{2}{*}{ Grade } & \multicolumn{2}{|c|}{ Observed } & \multicolumn{2}{|c|}{ SJS prediction } & \multicolumn{2}{|c|}{$\begin{array}{c}\text { Absolute } \\
\text { difference score }\end{array}$} \\
\hline & $M$ & $S D$ & $M$ & $S D$ & $M$ & $S D$ \\
\hline \multicolumn{7}{|l|}{ 3rd } \\
\hline Overall & 5.92 & 3.83 & 6.53 & 4.03 & 0.61 & 1.72 \\
\hline Female & 5.43 & 3.74 & 6.44 & 4.68 & 1.01 & 2.03 \\
\hline Male & 6.50 & 4.18 & 6.63 & 3.55 & 0.14 & 1.28 \\
\hline \multicolumn{7}{|l|}{ 6th } \\
\hline Overall & 7.37 & 2.45 & 8.76 & 1.97 & 1.40 & 2.15 \\
\hline Female & 8.44 & 2.01 & 8.83 & 2.23 & 0.39 & 1.40 \\
\hline Male & 5.75 & 2.27 & 8.66 & 1.69 & 2.91 & 2.28 \\
\hline \multicolumn{7}{|l|}{ 8th } \\
\hline Overall & 8.25 & 2.89 & 7.59 & 3.12 & 0.67 & 1.92 \\
\hline Female & 8.45 & 3.05 & 8.14 & 2.82 & 0.31 & 1.88 \\
\hline Male & 7.80 & 2.77 & 6.33 & 3.71 & 1.47 & 1.96 \\
\hline \multicolumn{7}{|l|}{ 11th } \\
\hline Overall & 7.21 & 3.65 & 8.61 & 2.81 & 1.40 & 2.09 \\
\hline Female & 7.93 & 2.91 & 9.51 & 1.28 & 1.57 & 2.23 \\
\hline Male & 4.50 & 5.26 & 5.25 & 4.57 & 0.75 & 1.50 \\
\hline
\end{tabular}

Note. SJS = social judgment schema. 
compared the actual observed group offers with the predictions of the SJS model. This model aggregates the individual offers of the three group members into one common group decision and predicts that the group offer will be determined by majority processes (see Davis, 1996; Ohtsubo, Masuchi, \& Nakanishi, 2002 for the SJS equations and experimental results). The SJS model is used as a baseline model for evaluating the relative influence of group members on the group decision. Any deviation from the prediction of the SJS model indicates that either a prosocial or a self-interested person is more influential in a group. We use the term "prosocial" to denote the group member with the highest individual offer in the group, whereas the "self-interested" participant is the member with the lowest individual offer.

Effects of age and sex on group decision processes. We calculated the difference score by subtracting the SJS model predictions from actual group offers and conducted a $2 \times 4$ ANOVA on the difference score with gender and grade as independent variables. The analysis revealed a significant interaction effect of Grade $\times$ Gender, $F(3,55)=2.91, p=.04, \eta_{\mathrm{p}}^{2}=.14$, and a significant main effect of grade, $F(3,55)=4.57, p=$ $.01, \eta_{\mathrm{p}}^{2}=.20$ (see Table 2 for means). To see how the actual group offers differed from SJS model predictions as a function of grade and gender, we conducted separate repeated-measures ANOVAs with actual group offers versus SJS prediction as a withinsubject variable for each gender in the four grades. Because the purpose of the ANOVA is to investigate model fit, keeping a 5\% significance level increases the risk of erroneously accepting a model. In keeping with previous research, we used a significance level of $20 \%$ to reject a tested model (see Kerr, Stasser, \& Davis, 1977).

Analyses revealed that the SJS model is rejected in three cases. In two cases, the actual group offers were lower than SJS model predictions, indicating that selfish minority children were more influential in groups that consisted of a generous majority: girls in 11th grade, $F(1,14)=7.45, p=.02, \eta_{\mathrm{p}}^{2}=.35$, and boys in 6th grade, $F(1,5)=9.74, p=.03, \eta_{p}^{2}=.66$. For boys in eighth grade, $F(1,4)=2.81, p=.17, \eta_{p}^{2}=.41$, the actual group offers were higher than the SJS prediction, indicating that prosocial children were more influential in the group. The SJS model fit the group decision-making process in the remaining five cases: In third grade, the group decision-making process followed the self-interested majority. In female groups in sixth grade as well as eighth grade, the group decision followed the generous majority. In male groups in 11th grade, the decision-making process followed the self-interested majority (see Table 2).
Moral reasoning and social influence. We first selected the groups in which the most prosocial offer was equal to or larger than $10(n=51)$. We further removed nine groups in which all three children made the same offer. In total, 42 groups with both prosocial and self-interested children who expressed conflict among different opinions were included in the analysis. For each group, we calculated the difference score in levels of moral reasoning between prosocial and self-interested children: First, the three group members were ranked according to their offers in the dictator game. If the individual offers of the first and second most generous children were closer than the offers of the second and the third most generous child, it was assumed that the first and second most generous children held prosocial opinions and the third child a self-interested opinion, and vice versa. Second, we calculated average levels of moral reasoning for prosocial individual(s) and self-interested individual(s) in a group. If there was no majority in a group (i.e., the difference between the first and the second most generous children's offers was equal to the difference between the second and the third, $n=$ 3), we assumed that a prosocial opinion was held by the first and second children and a self-interested opinion by the second and third children. In these three cases, we conducted the same analysis reported without using the second child's level of moral reasoning for the above calculation. The statistical results were only marginally influenced by this modification.

Using this procedure, the difference score in level of moral reasoning is positive if prosocial children are at a higher level of moral reasoning than self-interested children in the same group. We found that the difference score for the item of obligation to help others was significantly negatively correlated with how much the actual group offers shifted from the SJS majority model prediction in a selfish direction $(r=$ $-.39, p=.03$ ). Recall that the deviation of actual group offers from the SJS model prediction in a selfish direction represents the relative strength of social influence of self-interested children in a group. The correlation thus indicates that the higher the difference in level of moral reasoning (helping) between prosocial and self-interested children in favor of the prosocial children, the less the actual group offer shifted toward the selfish direction and vice versa. Or in other words, self-interested children were more influential in the group decision-making process when their level of moral reasoning was higher than that of prosocial children and vice versa. When moral reasoning was measured with promise keeping, the correlation did not reach the conventional significance 
level of $5 \%$ but the direction of correlation was the same $(r=-.24, p=.25)$. The two correlations were not significantly different from each other $(z=1.65, p>$ $.05)$.

\section{Justifications for Offers in the Group Discussion}

Table 3 shows how often each type of justification was mentioned during the group discussions in each grade. Whereas children from 3rd grade used predominantly the unconditional justifications self-interest and fairness for their offers, 6th-, 8th-, and 11thgrade participants increasingly employed group membership, reciprocity, and hierarchical power. From sixth grade on, fairness was used most frequently, and fairness was the second most commonly used justification in third grade. Because of the small number of observations for some categories, we performed statistical analyses of age differences only for the overall categories of unconditional and conditional justifications. A chi-square test for unconditional justifications revealed a significant grade effect, $\chi^{2}=49.84, d f=3, p=.00$. In third grade, unconditional justifications were used more often than expected, whereas in all other grades unconditional justifications were used less often than expected. Similarly, a chi-square test showed a significant grade effect for the conditional justifications, $\chi^{2}=88.28, d f=3, p=.00$. Children in third grade used these justifications less often than expected, but from sixth grade on, participants employed conditional justifications more often than expected.

Next, we investigated how participants justified specific offers. Offers were combined into three categories: (a) low offers $(0-4$ coins), (b) moderate offers (5-9 coins), and (c) generous offers (10 or more coins). The reason for differentiating between low and moderate offers was to capture the variance within the

Table 3

Percentage Use of Content Categories in Group Discussion

\begin{tabular}{lccrc}
\hline & \multicolumn{4}{c}{ Grade } \\
\cline { 2 - 5 } & 3rd & 6th & 8th & 11 th \\
\hline Fairness & 36 & 32 & 38 & 25 \\
Egoism & 47 & 15 & 9 & 21 \\
Group & 8 & 18 & 13 & 23 \\
Reciprocity & 2 & 21 & 18 & 16 \\
Hierarchical power & 8 & 14 & 22 & 15 \\
\hline
\end{tabular}

Note. The overall number of justifications per grade was used as the basis for calculating the percentages. Fifty-three statements were coded in 3rd grade, 131 in 6th grade, 82 in 8th grade, and 260 in 11th grade. unequal offers. We chose to label offers as low when they fell below $20 \%$ of the initial sum to be split. Offers larger than the equal split (10 coins) occurred quite infrequently.

Although older participants mentioned more conditional justifications than younger participants, no consistent age trend can be observed in their use to justify a specific offer. In all grades, fairness arguments were almost exclusively used to justify generous offers of 10 coins or more. Furthermore, in third-grade participants employed positive group attributions about the other group to justify high offers. For example, they argued that the other group was like them and that they should therefore get a fair share of the money. Participants of all age groups mentioned egoistic justifications when they were arguing for low and moderate offers. In third grade, the majority of low and moderate offers $(70 \%)$ were rationalized by giving egoistic justifications. Egoism remained an important justification for low and moderate offers in the older grades (used in $30-50 \%$ of cases), but participants additionally used negative conditional justifications. Children from sixth grade used negative group attributions $(30 \%)$ and negative reciprocity $(45 \%)$ to justify low and moderate offers. In eighth grade, hierarchical power justifications were often employed for low and moderate offers (46\%). Participants wanted to keep more than half for themselves because they felt that they had to invest more effort in making this decision than the other group and therefore deserved more. Participants from 11th grade justified low offers with negative group attributions $(24 \%)$ and negative reciprocity $(16 \%)$, whereas hierarchical power justifications were used for moderate offers $(30 \%)$.

\section{Discussion}

In this study, we investigated children's and adolescents' individual and group allocations in the dictator game and assessed the influence of fairness preferences and level of moral reasoning on individual offers. Further, we explored the process through which three group members arrived at a common group offer, evaluated which justifications they used for certain allocations in the group discussion, and examined the role of moral reasoning abilities in gaining social influence in group decision making.

\section{Individual Offers in the Dictator Game}

The results of this study show that children and adolescents act mostly prosocially and fairly in 
a situation where their material self-interests conflict with norms of fair sharing. In contrast to previous research by developmental psychologists (Damon, 1977; Fabes \& Eisenberg, 1998) as well as experimental economists (Harbaugh et al., 2000), we found no significant developmental effect for individual allocations. In the present study, participants allocated on average between $35 \%$ and $40 \%$ to the anonymous other players. Adult proposers offer on average only $20 \%$ of the resources to others (e.g., Camerer, 2003) and the children and adolescents in Harbaugh et al. (2000) previous study on the dictator game offered between $10 \%$ and $20 \%$. There may be several explanations for these different findings.

First, the difference in individual offers might be due to cultural norms concerning sharing in the United States and Germany. A few studies with adults have found cross-cultural variations concerning behavior in economic games (e.g., Hennig-Schmidt, Li, \& Yang, 2002; Henrich et al., 2005). Zhu, Keller, Chen, Mou, and Wang (2007) found that Chinese children and adolescents offered slightly but significantly more in the dictator game than German participants of the same-age groups. To test this hypothesis of cultural influences on dictator game offers, further cross-cultural studies with children and adolescents are necessary.

Second, the type of resources to be shared might influence individual allocations. In Harbaugh et al.s' (2000) study, tokens could be exchanged for money, toys, or school supplies at the end of the experiment. We decided to use money to make our results comparable to previous economic research with adults and oriented the monetary stakes according to the average weekly amount of students' pocket money. Economic studies with adults have shown little evidence that stake levels influence dictators' offers. For example, Forsythe et al. (1994) observed no difference between $\$ 5$ and $\$ 10$ dictator games (see also Cameron, 1999; Hoffman et al., 1994). Murnighan and Saxon (1998) found high correlations between monetary offers and M\&M candies offers for children and adolescents in the ultimatum game. However, the relationship between type and amount of resources, offers, and participants' age has yet to be systematically explored. We cannot rule out that particularly the youngest children were more generous than expected because money (as opposed to other resources) may be of less relevance for them than for older participants.

Third, although the dictator game situation was anonymous concerning the identity of the other group, the setting of three-person groups might make the situation feel more public and thus might lead to higher offers. Economic studies with adults have found only inconclusive results concerning the influence of "experimenter blindness" on the generosity of dictator game offers (e.g., Bolton \& Zwick, 1995; Hoffman et al., 1994). But a recent study by Haley and Fessler (2005) showed that adults allocated more money even when only subtle cues of observability, such as stylized eyes on the computer screen, were presented during a dictator game. On the other hand, Keller, Takezawa, Gummerum, Canz, and Petersen (2006) found no significant differences between individual offers in the present study and a control study of the same-age groups who played the dictator game with the same sums of money in a completely anonymous, double-blind condition. It also should be noted that most psychological research on distributive justice as well as previous studies on children's behavior in the dictator game are not anonymous in terms of experimenter blindness. Thus, social desirability influences in this study should be comparable to previous research on children's and adolescents' fair behavior.

In line with other developmental studies (Fabes \& Eisenberg, 1998; see also Leman, Keller, Takezawa, \& Gummerum 2006), we found that females were more generous than males. Developmental research has offered several explanations for such a gender effect. For example, parental behaviors, such as greater nurturance and affection, have been shown to be related to prosocial behaviors in children and are typically targeted more toward daughters than sons (e.g., Radke-Yarrow, Zahn-Waxler, \& Chapman, 1983). Helpful and altruistic behavior is generally considered as more appropriate for girls than for boys; girls are more likely to be reinforced for such actions by parents and teachers, whereas boys are more likely to be rewarded for prosocial behaviors that involve some risk taking (Power \& Shanks, 1989). These expectations regarding "appropriate" social behaviors for females and males might become more influential in puberty when adolescents try to follow the role expectations and stereotypes associated with their gender.

\section{Individual Offers and Their Relation to Social-Cognitive Variables}

As predicted, we found that participants' preferences for a fair allocation as assessed in a questionnaire influenced their behavior in the dictator game across all four age groups. Economists have assumed that sharing in the dictator game measures people's fairness preferences, but they have rarely related allocation behavior in this game to psychological 
variables (for an exception see Gunnthorsdottir, McCabe, \& Smith, 2002). This result can be taken to indicate that preferences for fair allocations are consistent with individual offers in the dictator game, and, as shown by Keller et al. (2006), with offers in a completely anonymous dictator situation.

The lack of developmental effects in both individual dictator game offers and fairness preferences is surprising, given that distributive justice tasks have found differences in the allocation principles most commonly used by children and adolescents (e.g., Damon, 1975, 1977; Hook \& Cook, 1979). In both the dictator game and the fairness preferences, task participants distribute money to anonymous others without further information about these persons. In these anonymous situations, in which participants have to construct the receivers, the equal split may be a default allocation that becomes dominant in individual behavior. Messick (1993) suggested that sharing equally represents a quick and cognitively less-demanding decision heuristic in situations that are novel, unfamiliar, and ambiguous. Equality can be used as an initial anchor from which adjustments for specific attributes of the receiver are made. Interestingly, participants seem to contextualize the other group, construct social information about a receiver (e.g., need, input), and justify their allocations in a sophisticated way in group discussions.

Level of moral reasoning was not associated with participants' individual sharing behavior, even though this study included participants from a wider age range than Takezawa et al.s' (2006) and we obtained developmental differences in moral reasoning similar to those of earlier studies in moral development research. Blasi (1980) noted in his metaanalysis that the relationship between level of moral reasoning and moral behavior increases if moral reasoning is assessed with Kohlberg's moral judgment interview instead of any other measure of moral reasoning. It is an open question whether we would have obtained a more positive relationship between moral reasoning and behavior in the dictator game if we had assessed moral reasoning with a comprehensive interview instead of a questionnaire.

\section{Group Decision-Making Process and Moral Reasoning}

Another goal of this study was to examine how same-aged peers reach a common group decision in the dictator game. We employed a social combination approach that allowed us to mathematically investigate the relative influence of group members with different individual allocation preferences on the group decision-making process. Although peer inter- actions have been identified as an important context for moral development, the social nature of moral decision making and reasoning has not been a major interest of moral developmental research (Saltzstein \& Kasachkoff, 2007).

Numerous studies in social psychology have demonstrated that majority processes are a default procedure when group members have different opinions in a judgment task (e.g., Hinsz et al., 1997; Stasser et al., 1989). Our analysis confirms these results. In most groups across all ages and genders, the group decision-making process followed the majority, be it a generous or a selfish one. The results of this study also indicate that it is essential not to merely compare mean differences in individuals' and groups' allocations because group offers are determined by both the distribution of individual preferences in each group and the group decision-making process.

In contrast to individual offers, moral reasoning level was important for gaining social influence during the group discussion. Our analyses revealed that a prosocial majority is more likely to defend its majority position and steer the group toward a prosocial offer if the moral reasoning level of the most prosocial group member is higher compared to the moral reasoning level of the most self-interested group member. Conversely, if the most self-interested group member's level of moral reasoning is higher than that of the most prosocial group member, the group offer becomes more selfish than predicted by the SJS majority model. Thus, level of moral reasoning increases the social influence of members in a group, buffers against the social influence of others, and helps defend one's own convictions and preferences. This is in line with Haidt's (2001) proposal that moral reasoning ability is important in an interpersonal context when people try to influence each other's judgments. We found that the relationship between moral reasoning level and social influence is particularly pronounced for the moral issue of helping others. Like helping, sharing with others can be seen as a positive moral duty that leaves more personal freedom for decision making than keeping a promise, a negative moral duty that we owe to everybody (Frankena, 1973). Therefore, the issue of helping might be more directly related to the behavior in question than the issue of promise keeping.

Level of moral reasoning is but one factor that might increase a group member's social influence during a group negotiation (for an overview see Moscovici, 1976). One variable that has been shown to affect social influence of majority and minority group members is group size. For example, Davis, $\mathrm{Au}$, Hulbert, Chen, and Zarnoth (1997) have pointed out 
that interaction in larger compared to smaller groups seems to foster behavior in line with the majority; the influence of a minority member decreases in larger groups. Even though similar effects have not been tested with children so far, it might be possible that the social influence of a self-interested or prosocial minority group member might not have been as strongregardless of his or her moral reasoning ability-had we studied larger groups. Unfortunately, there are no studies that allow comparing if similar processes of influence obtain when groups negotiate a moral decision in a classical moral dilemma (see Saltzstein \& Kasachkoff, 2007).

\section{Justifications for Offers in Group Discussions}

Participants of all age groups justified offers by referring to simple allocation principles of fairness when arguing for equality and to egoism when arguing for nonequality. This was particularly true for the youngest participants and supports Hook and Cook's (1979) proposition that young children focus on the outcome dimension when making allocation judgments. Older participants additionally employed conditional justifications that attribute characteristics to the other group. For example, they constructed the others in terms of needs, (dis-)similarities between the two groups, relative power versus responsibility of the deciding proposer group, and reciprocity in behavior. These spontaneous constructions mirror the allocation principles studied in distributive justice research (see Damon, 1975, 1977; McGillicuddyDe Lisi et al., 2006), such as neediness or effort invested, without supporting a clear-cut developmental sequence.

Participants employed elaborate conditional justifications when arguing for both equal and unequal offers, and in the latter case, they resembled moral justifications for rationalizing behavior that are inconsistent with normative demands (see Bandura, 1999; Bandura et al., 2001; Keller, 1984). Group discussions in the dictator game provide rich material for justifications that cannot usually be captured by distributive justice or (prosocial) moral reasoning research (see Eisenberg, 1986; Kohlberg, 1984). In this tradition, self-interested choices are almost exclusively justified with lower level reasons, such as authority, hedonism, or primitive needs. The present study indicates that older participants particularly employ complex justifications for self-interested offers, probably because equality represents the default fairness norm in the dictator game. Therefore, self-interested group members have to use complex justifications to convince others.
Together with the findings on moral reasoning ability and social influence, the results concerning participants' use of justifications indicate that social-cognitive processes, such as moral reasoning and perspective taking, influenced moral decision making in a group context, even though these processes did not play a role in individual sharing behavior. For future studies, we propose limiting participants' possible offers (e.g., to a low, a moderate, and a fair offer), which could help to focus the discussion and might result in more distinctive developmental effects in the use of justifications for offers.

\section{Caveats and Conclusion}

With this study, we have tried to pursue a new interdisciplinary connection between experimental economic research on fair behavior, the developmental psychology of fairness and prosocial and moral reasoning, and social psychological research on group decision making. However, there certainly are some methodological limitations that should be addressed in future research.

In this study, group members knew each other from previous classroom interactions. It is possible that interpersonal processes, such as friendships and differences in status, or the experimental design (i.e., being videotaped) influenced the group decisionmaking process, and we did not control for these aspects in the present study. Furthermore, because participants' individual offers were assessed in the same experimental session as the group decisions, the composition of groups concerning the individual preferences of the group members was random. For future studies, we would suggest measuring individual offers first and then systematically composing groups according to members' individual preferences. This would make it possible to examine whether a specific group composition (e.g., two children with a high offer and one child with a low one; two children with a low offer and one child with a high offer) leads to similar or different group decision-making processes in different age groups.

Both group and individual decisions could be affected by factors other than fairness preferences and moral reasoning ability, such as participants' general cognitive abilities or their orientation to peer groups, which themselves change over development. We used the mathematical social combination approach to model group decisions but did not address more qualitative processes of the group negotiation, such as children's argumentation style (see Keller \& Canz, 2007). Despite these limitations, 
we believe that including economic game theory and group experiments in the methodological toolbox of developmental psychologists provides an exciting new avenue for future research on the development of fair and moral behavior.

\section{References}

Abramovitch, R., Freedman, J. L., \& Pliner, P. (1991). Children and money: Getting an allowance, credit versus cash, and knowledge of pricing. Journal of Economic Psychology, 12, 27-45.

Azmitia, M., \& Perlmutter, M. (1989). Social influence on children's cognition: State of the art and future directions. Advances in Child Development and Behavior, 22, $89-144$.

Bandura, A. (1999). Moral disengagement in the perpetration of inhumanities. Personality and Social Psychology Review, 3, 193-209.

Bandura, A., Caprara, G. V., Barbaranelli, C., Pastorelli, C., \& Regalia, C. (2001). Sociocognitive self-regulatory mechanisms governing transgressive behavior. Journal of Personality and Social Psychology, 80, 125-135.

Berkowitz, M. W., \& Gibbs, J. C. (1983). Measuring the developmental features of moral discussions. MerrillPalmer Quarterly, 29, 399-410.

Berkowitz, M. W., \& Gibbs, J. C. (1985). The process of moral conflict resolution and moral development. In M. W. Berkowitz (Ed.), Peer conflict and psychological growth. New directions for child development, no. 29 (pp. 71-83). San Francisco: Jossey-Bass.

Berti, A. E., \& Bombi, A. S. (1981). The development of the concept of money and its value: A longitudinal study. Child Development, 52, 1179-1182.

Bettinger, E., \& Slonim, R. (2006). Using experimental economics to measure the effects of a natural educational experiment on altruism. Journal of Public Economics, 90, 1625-1648.

Blasi, A. (1980). Bridging moral cognition and moral action: A critical review of the literature. Psychological Bulletin, 88, 1-45.

Bloom, P. (2004). Decartes' baby. How the science of child development explains what makes us human. New York: Basic Book.

Bolton, G. E., \& Zwick, R. (1995). Anonymity versus punishment in ultimatum bargaining. Games and Economic Behavior, 10, 95-121.

Bornstein, G., \& Yaniv, I. (1998). Individual and group behavior in the ultimatum game: Are groups more "rational" players? Experimental Economics, 1, 101108.

Camerer, C. F. (2003). Behavioral game theory: Experiments in strategic interaction. Princeton, NJ: Princeton University Press.

Cameron, L. A. (1999). Raising the stakes in the ultimatum game: Experimental evidence from Indonesia. Economic Inquiry, 27, 47-59.
Cason, T. N., \& Mui, V.-L. (1997). A laboratory study of group polarization in the team dictator game. Economic Journal, 107, 1465-1483.

Damon, W. (1975). Early conceptions of positive justice as related to the development of logical operations. Child Development, 46, 301-312.

Damon, W. (1977). The social world of the child. San Francisco: Jossey-Bass.

Davis, J. H. (1973). Group decision and social interaction: A theory of social decision schemes. Psychological Review, $80,97-125$.

Davis, J. H. (1996). Group decision making and qualitative judgments: A consensus model. In E. Witte \& J. H. Davis (Eds.), Understanding group behavior: Consensual action by small groups (Vol. 1, pp. 35-59). Mahwah, NJ: Lawrence Erlbaum.

Davis, J. H., Au, W. T., Hulbert, L., Chen, X.-P., \& Zarnoth, P. (1997). Effects of group size and procedural influence on consensual judgments of quantity: The example of damage awards and mock civil juries. Journal of Personality and Social Psychology, 73, 703-718.

Eisenberg, N. (1986). Altruistic emotion, cognition, and behavior. Hillsdale, NJ: Erlbaum.

Epps, T. W., \& Singleton, K. (1986). An omnibus test for the two-sample problem using the empirical characteristic function. Journal of Statistical Computation and Simulation, 26, 177-203.

Fabes, R. A., \& Eisenberg, N. (1998). Meta-analyses of age and sex differences in children's and adolescents' prosocial behavior (Working paper). Arizona State University.

Forsythe, R., Horowitz, J. L., Savin, N. E., \& Sefton, M. (1994). Fairness in simple bargaining games. Games and Economic Behavior, 6, 347-369.

Frankena, W. K. (1973). Ethics. London: Prentice Hall.

Gibbs, J. C., \& Widaman, K. F. (1982). Social intelligence: Measuring the development of socio-moral reflection. Englewood Cliffs, NJ: Prentice Hall.

Gunnthorsdottir, A., McCabe, K., \& Smith, V. (2002). Using the Machiavellianism instrument to predict trustworthiness in a bargaining game. Journal of Economic Psychology, 23, 49-66.

Haidt, J. (2001). The emotional dog and its rational tail: A social intuitionist approach to moral judgment. Psychological Review, 108, 417-449.

Haley, K. J., \& Fessler, D. M. T. (2005). Nobody's watching? Subtle cues affect generosity in an anonymous economic game. Evolution and Human Behavior, 26, 245-256.

Harbaugh, W. T., \& Krause, K. (2000). Children's altruism in public good and dictator experiments. Economic Inquiry, 38, 95-109.

Harbaugh, W. T., Krause, K., \& Liday, S. (2000). Children's bargaining behavior: Differences by age, gender, and height (Working paper). University of Oregon.

Hennig-Schmidt, H., Li, Z.-Y., \& Yang, C. (2002). Nonmonotone strategies in ultimatum bargaining: First results from a video experiment in the People's Republic of China. In Proceedings of the International Congress of Mathematicians Game Theory and Applications Satellite 
Conference (pp. 225-231). Qingdao: Qingdao Publishing House.

Henrich, J., Boyd, R., Bowles, S., Gintis, H., Fehr, E., Camerer, C., et al. (2005). 'Economic man' in crosscultural perspective: Ethnography and experiments from 15 small-scale societies. Behavioral and Brain Sciences, 28, 795-855.

Hinsz, V. B., Tindale, R. S., \& Vollrath, D. A. (1997). The emerging conceptualization of groups as information processors. Psychological Bulletin, 121, 43-64.

Hirschfeld, L. A. (1995). Do children have a theory of race? Cognition, 54, 209-252.

Hoffman, E., McCabe, K., Shachat, K., \& Smith, V. (1994). Preferences, property rights, and anonymity in bargaining games. Games and Economic Behavior, 7, 346-380.

Hook, J. G., \& Cook, T. D. (1979). Equity theory and the cognitive ability of children. Psychological Bulletin, 86, $429-445$.

Kahneman, D., Knetsch, J. L., \& Thaler, R. H. (1986). Fairness and the assumptions of economics. Journal of Business, 59, 285-300.

Keller, M. (1984). Rechtfertigungen. Zur Entwicklung praktischer Erklärungen. In W. Edelstein \& J. Habermas (Eds.), Soziale Interaktion und soziales Verstehen (pp. $253-$ 299). Frankfurt am Main, Germany: Suhrkamp.

Keller, M., \& Canz, T. (2007). Zwischen Fairness und Interesse: Eine entwicklungs-psychologische Studie zu Verhandlungen in Gruppen. In A. Bucher (Ed.), Moral, Religion, Politik: Psychologisch-Paedagogische Zugaenge. Festschrift fuer Fritz Oser (pp. 113-139). Wien: LIT Verlag.

Keller, M., \& Edelstein, W. (1993). The development of a moral self from childhood to adolescence. Moral Education Forum, 18, 1-18.

Keller, M., Takezawa, M., Gummerum, M., Canz, T., \& Petersen, M. (2006, July). Selfish or fair? Group negotiations about sharing. Paper presented at the 32 nd Conference of the Association for Moral Education, Fribourg, Switzerland.

Kerr, N. L., Stasser, G., \& Davis, J. H. (1977). Model-testing, model-fitting, and social decision schemes. Organizational Behavior and Human Decision Processes, 23, 399410.

Kohlberg, L. (1984). The psychology of moral development: Essays on moral development. San Francisco: Harper \& Row.

Krebs, D. L., \& Van Hesteren, F. (1994). The development of altruism: Toward an integrative model. Developmental Review, 14, 103-158.

Leman, P. J., Ahmed, S., \& Ozarow, L. (2005). Gender, gender relations, and the social dynamics of children's conversations. Developmental Psychology, 41, 64-74.

Leman, P. J., Keller, M., Takezawa, M., \& Gummerum, M. (2006). Children's and adolescents' decisions about sharing money with others. Manuscript submitted for publication.

McGillicuddy-De Lisi, A. V., Daly, M., \& Neal, A. (2006). Children's distributive justice judgments: Aversive racism in Euro-American children? Child Development, 77, $1063-1080$.
Messick, D. M. (1993). Equality as a decision heuristic. In B. A. Mellers \& J. Baron (Eds.), Psychological perspectives on justice (pp. 11-31). New York: Cambridge University Press.

Moscovici, S. (1976). Social influence and social change. London: Academic Press.

Murnighan, J. K., \& Saxon M. S. (1998). Ultimatum bargaining by children and adults. Journal of Economic Psychology, 19, 415-445.

Ohtsubo, Y., Fujita, M., \& Kameda, T. (2004). How can psychology contribute to designing a mixed jury system in Japan? Ongoing debates and a thought experiment. In Y. Kashima, Y. Endo, E. Kashima, C. Leung, \& J. McClure (Eds.), Progress in Asian social psychology (pp. 289-309). Seoul: Kyoyook-kwahak-sa.

Ohtsubo, Y., Masuchi, A., \& Nakanishi, D. (2002). Majority influence process in group judgment: Test of the social judgment scheme model in a group polarization context. Group Processes and Intergroup Relations, 5, $249-261$.

Piaget, J. (1965). The moral judgment of the child. New York: Harcourt.

Power, T. G., \& Shanks, J. A. (1989). Parents as socializers: Maternal and paternal views. Journal of Youth and Adolescence, 18, 203-220.

Radke-Yarrow, M., Zahn-Waxler, C., \& Chapman, M. (1983). Children's prosocial dispositions and behavior. In P. H. Mussen (Ed.), Charmichael's manual of child psychology (Vol. 4, pp. 469-546). New York: Wiley.

Ram, A., \& Ross, H. S. (2001). Problem solving, contention, and struggle: How siblings resolve a conflict of interest. Child Development, 72, 1710-1722.

Sally, D., \& Hill, E. (2006). The development of interpersonal strategy: Autism, theory-of-mind, cooperation and fairness. Journal of Economic Psychology, 27, 73-97.

Saltzstein, H. D., \& Kasachkoff, T. (2007, June). A psychological and philosophical critique of intuitionist-evolutionary theories of morality. Paper presented at the 37th Annual Meeting of the Jean Piaget Society, Amsterdam, The Netherlands.

Schopler, J., \& Insko, C. (1992). The discontinuity effect in interpersonal and intergroup relations: Generality and mediation. European Review of Social Psychology, 3, 121 151.

Song, F., Cadsby, C. B., \& Morris, T. (2006). Other-regarding behavior and behavioral forecasts: Females versus males as individuals and group representatives. International Journal of Conflict Management, 15, 340-363.

Stasser, G., Kerr, N. L., \& Davis, J. H. (1989). Influence processes and consensus models in decision making in groups. Hillsdale: Lawrence Erlbaum.

Takezawa, M. (2003, December). Two distinct proximate causes of strong-reciprocity. Poster presented at the 4 th Goettinger Freilandtage, Goettingen, Germany.

Takezawa, M., Gummerum, M., \& Keller, M. (2006). A social world for the rational tail of the emotional dog. Roles of moral reasoning in group decision making. Journal of Economic Psychology, 27, 117-139. 
Turiel, E. (1983). The development of social knowledge: Morality and convention. Cambridge: Cambridge University 7 Press.

Walker, L. J., Hennig, K. H., \& Krettenauer, T. (2000). Parents and peer contexts for children's moral reasoning development. Child Development, 71, 1033-1048.
Youniss, J. (1980). Parents and peers in social development. Chicago, IL: University of Chicago Press.

Zhu, L., Keller, M., Chen, D., Mou, Y., \& Wang, F. (2007, March). Egoism or altruism: How Chinese children play economic games. Paper presented at Biennial Meeting of the Society for Research in Child Development, Boston. 


\section{Author Query Form}

\section{Journal: Child Development \\ Article : cove1143}

Dear Author,

During the copy-editing of your paper, the following queries arose. Please respond to these by marking up your proofs with the necessary changes/additions. Please write your answers on the query sheet if there is insufficient space on the page proofs. Please write clearly and follow the conventions shown on the attached corrections sheet. If returning the proof by fax do not write too close to the paper's edge. Please remember that illegible mark-ups may delay publication.

Many thanks for your assistance.

Query

Query

Remark

No.

$1 \quad$ Please provide the publisher location for reference "Fabes and Eisenberg (1998)."

2 Please provide the publisher location for reference "Harbaugh et al. (2000)."

3 Please provide the editors names (if any) and publisher country name for reference "Hennig-Schmidt et al. (2002)."

$4 \quad$ Please provide the publisher country name for reference "Keller and Canz (2007)."

5 Please provide the publisher country name for reference "Ohtsubo et al. (2004)."

6 Please provide the publisher country name for reference "Stasser et al. (1989)."

$7 \quad$ Please provide either the state (if in U.S.) or the country (other than U.S.) of the publisher for reference "Turiel (1983)." 